ORIGINAL ARTICLE

\title{
Sources of variability in uncertain medical decisions in the ICU: a process tracing study
}

\section{O Kostopoulou, M Wildman}

See end of article for authors' affiliations

....................

Correspondence to: Dr O Kostopoulou, Research Fellow, Department of Primary Care and General Practice, University of Birmingham, Birmingham B15 2TT, UK;

o.kostopoulou@

bham.ac.uk

Accepted for publication 3 May 2004
Background: Consistency of medical decision making (equity) is an important component of quality of care. When patients with chronic obstructive pulmonary disease (COPD) present with an exacerbation needing respiratory support they may die if it is not provided. However, if the disease has reached its terminal stage, ventilation will prolong the process of dying. The ventilation outcome is uncertain and there is evidence of variability when this decision is made, the sources of which are not well understood.

Objectives: To identify sources of variability and propose ways of tackling them in order to promote equity in this type of medical decision.

Methods: Six case histories were selected from hospital records of COPD patients. Fourteen senior doctors from seven hospitals in the West Midlands participated. A process tracing approach was used which consisted of (1) withholding case information until specifically requested by the doctors, (2) estimating survival during the decision making process, and (3) concurrent questioning regarding information interpretation and its impact on survival estimates and decisions.

Results: The observed decision variability was attributed to doctors attaching importance to different information, gathering different information, and interpreting information differently. There were significant differences between doctors in the amount of information requested.

Conclusions: Differences in information gathering and interpretation by clinicians can result in different decisions being made about the same patient. This variation may exist for other uncertain medical decisions and may be tackled by providing clinicians with prognostic models in the form of usable decision aids.
$\mathrm{F}$ our principal factors have been identified as determinants of the observed variation in healthcare practice: patient, clinician, institution, and environment. ${ }^{1}$ Keeping all other factors constant, the knowledge that different doctors will make the same decision about the same patient under identical conditions is reassuring. If, however, the decision varies according to who makes it, then it is reasonable to question whether the principles of equity and quality of care are being upheld. It is also imperative to look into the causes of such variation.

Chronic obstructive pulmonary disease (COPD) is a progressive and irreversible respiratory disease with death rates similar to that of lung cancer. ${ }^{2}$ Disease progression is often characterised by a series of exacerbations which may require ventilatory support. If such support is not provided, the patient may die from respiratory failure. Patients with COPD account for about $2.5 \%$ of critical care admissions in the UK. ${ }^{3}$ Admission to the intensive care unit (ICU) and mechanical ventilation can return some COPD patients to their pre-existing level of functioning. If, however, the terminal phase of the disease has been reached, ventilation will be futile and will prolong the process of dying. Furthermore, mechanical ventilation is not without disadvantages and risks. ${ }^{4}$ Clinicians therefore need to assess if the patient is likely to receive "sustained benefit in terms of quality and length of life" from ICU admission. ${ }^{5}$

Outcome prediction is difficult before ventilation is started ${ }^{6}$ and the accuracy of clinicians in outcome prediction has been questioned..$^{7-9}$ A study by Pearlman and colleagues ${ }^{10}{ }^{11}$ of decision making in this area, using one vignette of an elderly debilitated patient with COPD in extremis, found that survival estimates ranged from 1 month to 5 years and were highly correlated with treatment decisions. When the 205 US doctors who participated in the study were asked to explain their decision, non-intubators most frequently referred to the patient's poor quality of life and the terminal stage of the disease while intubators most frequently talked about the clinical situation being reversible. Since explanations and survival estimates were given after the decision had been made, we cannot assume that they were more than justifications. Questions therefore remain as to the source of the observed differences.

ICUs will admit patients with clearly reversible disease but not terminally ill patients. For the rest of the patients with progressive diseases such as COPD, the uncertainty regarding their prognosis could lead to a low level of agreement. Agreement between judges has been identified as a necessary condition for expertise, ${ }^{12}$ but the more uncertain and unstructured the judgment task, the lower the level of agreement. ${ }^{13}$ We do not know how clinicians deal with uncertainty in this type of decision and the origins of the variability.

This study aimed to identify sources of variability in the decision to ventilate or not a known patient with COPD in acute respiratory failure. The study concentrated on clinician cognition by tracing the reasoning processes of experienced clinicians while they were making their decision.

As in the study by Pearlman et al, ${ }^{10} 11$ "paper patients" were used but case information was presented gradually upon request rather than all at once. Survival estimates and information interpretations were made during the reasoning process rather than at the end to avoid post-decision rationalisations.

\section{METHODS}

\section{Participants}

Participants were selected purposively. We aimed to include only doctors who regularly make ICU "gatekeeping" decisions for COPD patients-that is, respiratory and 
intensive care doctors. We wanted doctors at the highest level of training in the specialty (consultant grade), assuming that they would have acquired through experience optimal strategies for making the decision. Finally, we aimed to select consultants with a wide range of experience (number of years) in that grade. Using these criteria, the head of the Heart of England Critical Care Network identified 20 consultants from hospitals in the West Midlands who were invited to participate. Six were unable to agree to take part, leaving 14 consultants (seven in respiratory medicine and seven in anaesthesia and intensive care) from seven hospitals to participate in the study. Experience in the current grade ranged from 3 to 21 years for respiratory consultants and from 3 to 22 years for intensive care consultants.

\section{Materials}

Six case histories were selected from hospital records of COPD patients who had been considered for admission at a local ICU. The participants were not informed of the actual decision and outcome of each case. The criterion for case selection was the completeness of the hospital record. Moreover, cases were selected to represent a wide range of disease severity.

Descriptions of exercise tolerance were standardised by combining the functional score categories of Menzies et al ${ }^{14}$ (independent, restricted, housebound, bedbound) with the index of Independence in the Activities of Daily Living. ${ }^{15}$ This is a scale that reflects dependencies in the ability to care for oneself (bathing, dressing, toileting, continence, transfer in and out of bed/chair, walking and eating) and is appropriate for people with severe functional limitations. All patients could perform self-care except for case 5 who needed help with washing. There were three "restricted" patients (able to live on his/her own and get out of the house to do basic necessities but severely limited in exercise ability; stops for breath after walking about 100 yards or after a few minutes on the level) and three "housebound" patients (cannot get out of house unassisted or gets out only rarely; unable to do heavy chores such as house cleaning; cannot live alone; has to stop frequently on the stairs).

\section{Procedure}

Ethical approval was obtained from the West Birmingham local research ethics committee. The doctors were visited individually by one of the investigators (OK) between February and April 2002 at their workplace and the aims of the study and the procedure were explained. Participants were given a written scenario introducing all six cases in the same way:

A known COPD patient had been admitted to hospital with an exacerbation, had received conventional therapy, but was not responding and was currently very unwell and highly likely to arrest if not intubated and ventilated. Due to hospital commitments, they could not go to see the patient but the Senior House Officer had all the relevant information and investigations for making the decision.

This is all that the participants were initially told about each patient. They could then ask the investigator for further information from a list (box 1) which was available to them. Each time a new item of information was revealed, participants were asked to record it at the top of an answer sheet and subsequently to (1) estimate probabilities for ICU survival, hospital survival and 6 month survival following discharge from hospital (on $100 \mathrm{~mm}$ visual analogue scales), (2) assess quality of life at 6 months following ventilation and discharge on a 5 point scale ranging from "poor" to "excellent", and (3) make a preliminary decision regarding admission (yes/no/cannot decide yet). Participants recorded each new item of information requested at the top of a new answer sheet and then answered these three questions again. This procedure continued until participants felt that more information would not change their decision. In this way, a record was kept of what information was requested, in what sequence, and at what point estimates or decisions were updated or finalised. To ensure comparability between doctors they were all presented with the same six cases in the same order.

\section{Process tracing}

Withholding all case information initially and revealing it sequentially upon request enabled us to follow the decision making process over time step by step. The "withheld information" technique ${ }^{16}$ reveals the partially covert process of data gathering. The method has been used for training ${ }^{17}$ and knowledge capture ${ }^{18}$ of process control operators and is similar to process tracing techniques such as "active information search" (AIS) $)^{19}$ and "conversational AIS" ${ }^{\prime 20}$ used for studying aspects of non-expert decision making. They involve participants asking the investigator questions in order to obtain information to reach a decision.

However, making the data gathering process overt provides little insight into data interpretation and impact on decisions. ${ }^{20}$ "Think aloud" has therefore been used to complement process tracing. ${ }^{20}$ This requires that participants are first trained on unrelated problems ${ }^{21}$ so the overall time of involvement increases. This could have made recruitment difficult, so an alternative approach was used to gain insight into information interpretation: participants were asked to comment on the information that they had just gathered ("What did this last information tell you?" or "Why did you just increase/reduce survival estimates?") or were about to gather ("Why do you need this information?"). When people report on the immediately previous cognitive process, considerable episodic memory can be retrieved, helped by information still held in short term memory. ${ }^{21}$ Moreover, when people are asked to report rules, concepts and hypotheses immediately before or after performance before any feedback is provided,

Box 1 Types of information available (in alphabetical order)

- Age

- Allergies

- Arterial blood gases on admission

- Chest $x$ ray

- COPD history

- Current medications

- ECG

- Exercise tolerance (in the period of stability)

- Findings on examination

- Full blood count

- History of presenting complaint

- Liver function tests

- Past medical history

- Presenting complaint

- Recent hospital admissions with shortness of breath (SoB)

- Self-rated quality of life

- Sex

- Smoking

- Social history

- Urea and electrolytes 
these are consistent with performance. ${ }^{21}$ Participants' verbalisations were therefore taken to reflect their actual reasoning process. All concurrent commentary was recorded and transcribed. The whole process lasted an average of 1 hour. Three participants did not attempt case 6 due to lack of time.

\section{Analysis of data}

Estimating differences between doctors, specialities, cases, and decisions

$\chi^{2}$ tests were used to compare decision differences between speciality groups (respiratory and intensive care doctors) and between cases, Mann-Whitney tests were used to analyse differences in survival estimates and in the amount of information requested between yes/no decisions and between speciality groups, and the Kruskall-Wallis test was used for differences between doctors.

\section{Identifying decision predictors}

Stepwise multiple regression analysis was carried out to identify possible combinations of factors that were predictive of the final decision. Variables entered into the modelling process were final survival estimates, estimated quality of life at 6 months, age, and exercise tolerance. Age and exercise tolerance were chosen because most participants in most cases requested them. Three age groups were defined: $<70$, $70-80$, and 80+. SPSS 11.0 was used for the analyses.

\section{Mapping out the reasoning process}

Qualitative data can be arranged in time ordered matrices to track processes over time. ${ }^{22}$ This is especially suited to process tracing data which shows how reasoning unfolds leading to a decision. The data went through cycles of reduction, organisation, inference and verification, as described below.

Three types of critical activity were extracted from the answer sheets and the transcripts: (1) information gathering, (2) survival estimates and decisions, and (3) comments, either prompted or spontaneous. The activities of each clinician on each case were arranged in tables in chronological order; an example is shown in fig l. From each of these time ordered tables the reasons for the decision were inferred in an iterative process by going back to the transcripts. Requesting an item of information did not necessarily mean that it was used by the clinician, so only information that was commented upon or led to immediate changes in survival estimates or an immediate decision was considered influential. The correspondence between comments and estimates served as a means of verifying inferences. Where inconsistencies were observed, no inferences were drawn.

The reasons for decisions were aggregated in admission and non-admission tables for each case-for example, case 4 in tables 1 and 2. Comparisons were made within and between admission and non-admission tables for each case, looking for similarities and differences in reasons.

\section{RESULTS \\ Differences between doctors, specialities, cases, and decisions}

The final decision of each participant on each of the six cases is shown in table 3.

There was a significant association between cases and decisions $\left(\chi^{2}=27, \mathrm{df}=5, \mathrm{p}<0.001\right)$ with case 1 being consistently admitted and case 5 being consistently refused admission. Decisions on cases 2, 3 and 4 varied: case 2 was refused admission by four participants $(29 \%)$, case 3 by six participants $(43 \%)$, and case 4 by six participants $(43 \%)$. There was no significant association between specialities and decisions $(p=0.75)$.

Doctors differed significantly in the amount of information requested $\left(\chi^{2}=52, \mathrm{df}=13, \mathrm{p}<0.001\right)$ with averages ranging from 1.8 items (Resp1) to 13.3 items (ICU2). No significant differences were found between admission/non-admission decisions $(p=0.80)$, specialities $(p=0.30)$, and cases $(\mathrm{p}=0.94)$.

Survival estimates for ICU, hospital, and at 6 months were significantly higher for admission than non-admission decisions (all $\mathrm{p}<0.001$ ).

\section{Decision predictors}

The final model included only 6 month survival as a significant predictor: the odds of admitting a patient were increased by $9 \%$ for every $1 \%$ increase in estimated 6 month survival (95\% CI 1.05 to 1.11 ).

\section{Mapping out the reasoning process}

Figure 1 shows the decision making process of participant Resp4 on case 4 and illustrates how the process was mapped out and the types of inferences drawn. The items of information requested are numbered in the sequence requested. Comments, survival estimates, and decisions are presented at the points at which they were made in the process.

Early on, Resp4 formulated two hypotheses regarding the cause of the current exacerbation: "... may be infection, may be another co-morbid condition" (comment 2). Support for one of the hypotheses was subsequently found: "... most likely he has COPD compounded by severe congestive heart failure" (comment 3). No attempt was made to check the infection hypothesis. Frequent hospital admissions were taken as evidence of severity of the combination of congestive heart failure (CHF) and COPD (comment 3). The blood gases confirmed this and led to the decision (comments 4 and 5). We cannot know how age and history of presenting complaint were used as they were not commented upon and did not lead individually to changes in estimates. Exercise tolerance, initially assessed as "good" (comments 1 and 2), appeared to become less important as more information was collected.

\section{Sources of decision variation}

Three sources of decision variation were identified:

- participants attached importance to different information about a case;

- participants requested different information about a case;

- participants interpreted the same information about a case differently.

Case 4 (see Appendix) will be used as an example.

\section{Attaching importance to different information}

Six participants refused admission to case 4 (table 1). They tended to concentrate on COPD severity, suggested by the frequent hospital admissions and the blood gases. The presence of CHF was considered a compounding factor by most.

Eight participants admitted case 4 (table 2). Seven did so mainly on the basis of exercise tolerance:

"Exercise tolerance is really the best way of finding out how bad his COPD and the CHF are." (ICU6)

"Someone who's got lots of bad things going, but mobilises relatively well." (Resp3)

This clustering of reasons for admission and reasons for non-admission was also observed in the other cases in which there was decision variation (cases 2 and 3). Decisions to admit case 2 were mainly based on perceived reversibility (suggested by blood gases and signs of pneumonia) and co-morbidities perceived as insignificant. Non-admission decisions were based on exercise tolerance (housebound). Case 3 was admitted due to a combination of insignificant comorbidities, lack of recent admissions, and ability to perform 


\begin{tabular}{|c|c|c|c|c|c|}
\hline \multicolumn{6}{|c|}{ INFORMATION GATHERING } \\
\hline \multicolumn{6}{|c|}{$\begin{array}{l}\text { 1. History of presenting complaint: Increasing shortness of breath for } 4 \text { weeks. Rapid deterioration over the } \\
\text { last } 12 \text { hours. Gradual reduction in exercise tolerance. Housebound for the last week. } \\
\text { 2. Exercise Tolerance: 'Restricted' (definition given), can perform self-care. }\end{array}$} \\
\hline \multicolumn{6}{|c|}{ COMMENT 1 (UNPROMPTED) } \\
\hline \multirow[t]{2}{*}{ ESTIMATING SURVIVAL } & ICU & hospital & 6 months & QoL & Decision \\
\hline & 70 & 80 & 80 & Very good & Not yet \\
\hline \multicolumn{6}{|c|}{ COMMENT 2 (UNPROMPTED) } \\
\hline \multicolumn{6}{|c|}{$\begin{array}{l}\text { Resp4: 'Just on the basis of these, I think this is someone who has got a good exercise tolerance with not the } \\
\text { greatest ability. Increasing breathlesness over the last } 4 \text { weeks with rapid deterioration over this, may be } \\
\text { infection, may be another co-morbid condition.' }\end{array}$} \\
\hline \multicolumn{6}{|c|}{ INFORMATION GATHERING } \\
\hline \multicolumn{6}{|c|}{$\begin{array}{l}\text { 3. Recent hospital admissions with shortness of breath: } 3 \text { admissions in past } 6 \text { months. } \\
\text { 4. Co-morbidities: Known congestive heart failure. } \\
\text { 5. Age: } 72\end{array}$} \\
\hline \multirow[t]{2}{*}{ ESTIMATING SURVIVAL } & ICU & hospital & 6 months & QoL & Decision \\
\hline & 40 & 50 & 50 & Fair & Not yet \\
\hline \multicolumn{6}{|c|}{ COMMENT 3 (UNPROMPTED) } \\
\hline \multicolumn{6}{|c|}{$\begin{array}{l}\text { Resp4: 'He is known to have congestive heart failure, } 3 \text { admissions with breathlessness over the last } 6 \\
\text { months, so been in hospital very frequently, most likely he has COPD compounded by severe congestive } \\
\text { heart failure. Little benefit from ICU. I am between not to decide as yet or not to admit to ICU, let me see...' } \\
\text { (Reviews evidence so far) }\end{array}$} \\
\hline \multicolumn{6}{|c|}{ INFORMATION GATHERING } \\
\hline \multicolumn{6}{|c|}{ 6. Blood gases: on $35 \% \mathrm{O}_{2}, \mathrm{PaO}_{2}=6.2 \mathrm{kPa}, \mathrm{PaCO}_{2}=8.6 \mathrm{kPa}, \mathrm{pH}=7.32, \mathrm{HCO}_{3}^{-}=30.4 \mathrm{mmol} / \mathrm{l}$} \\
\hline \multicolumn{6}{|c|}{ COMMENT 4 (UNPROMPTED) } \\
\hline \multicolumn{6}{|c|}{$\begin{array}{l}\text { Resp4: 'I think the only change would be to drop his probability of being alive } 6 \text { months later and I would not } \\
\text { admit to ICU.' }\end{array}$} \\
\hline \multirow[t]{2}{*}{ ESTIMATING SURVIVAL } & ICU & hospital & 6 months & QoL & Decision \\
\hline & 40 & 50 & 40 & Fair & No \\
\hline \multicolumn{6}{|l|}{ COMMENT 5 (PROMPTED) } \\
\hline \multicolumn{6}{|c|}{ OK: Why did you decide not to admit? } \\
\hline \multicolumn{6}{|c|}{$\begin{array}{l}\text { Resp4: 'The blood gases tell me that this chap has chronic respiratory failure with very high bicarbonate } \\
\text { suggesting fairly severe COPD compounded by congestive heart failure. So probably he is not going to } \\
\text { benefit from ICU admission.' }\end{array}$} \\
\hline
\end{tabular}

Figure 1 Example of time ordered table (Resp4 on case 4).

Table 1 Aggregate non-admission table for case 4

\begin{tabular}{|c|c|c|}
\hline Participant & Reason for not admitting & Suggested by \\
\hline ICUI & $\begin{array}{l}\text { COPD severity } \\
\text { Nothing reversible }\end{array}$ & $\begin{array}{l}\text { Three recent hospital admissions } \\
\text { No signs of chest infection }\end{array}$ \\
\hline ICU2 & $\begin{array}{l}\text { COPD severity } \\
\text { CHF }\end{array}$ & $\begin{array}{l}\text { Three recent hospital admissions } \\
\text { [INFORMATION GIVEN] }\end{array}$ \\
\hline Resp2 & $\begin{array}{l}\text { COPD severity } \\
\text { Nothing reversible }\end{array}$ & $\begin{array}{l}\text { Three recent hospital admissions and blood } \\
\text { gases indicating } \mathrm{CO}_{2} \text { retention }\end{array}$ \\
\hline Resp4 & $\begin{array}{l}\text { COPD severity } \\
\text { CHF }\end{array}$ & $\begin{array}{l}\text { Three recent hospital admissions and blood } \\
\text { gases (high HCO } \mathrm{HCO}_{3} \text { ) } \\
\text { [INFORMATION GIVEN] }\end{array}$ \\
\hline $\mathrm{ICU} 4$ & $\mathrm{CHF}$ & [INFORMATION GIVEN] \\
\hline Resp7 & $\begin{array}{l}\text { COPD severity } \\
\text { Another suspected co-morbidity }\end{array}$ & $\begin{array}{l}\text { Blood gases } \\
\text { Blood gases }\end{array}$ \\
\hline
\end{tabular}




\begin{tabular}{|lll|}
\hline Table 2 & Aggregate admission table for case 4 & \\
\hline Participant & Reason for admitting & Suggested by \\
\hline Resp1 & Exercise tolerance & [INFORMATION GIVEN] \\
Resp3 & Exercise tolerance & [INFORMATION GIVEN] \\
ICU5 & Exercise tolerance & [INFORMATION GIVEN] \\
ICU6 & Exercise tolerance & [INFORMATION GIVEN] \\
ICU7 & Exercise tolerance & [INFORMATION GIVEN] \\
Resp5 & Exercise tolerance & [INFORMATION GIVEN] \\
& Reversible conditions (pneumonia, CHF) & \\
Resp6 & Exercise tolerance & [INFORMATION GIVEN] \\
& Good metabolic rate & Blood gases \\
ICU2 & CHF survived heart attack & \\
\hline CHF, congestive heart failure. & \\
\hline
\end{tabular}

self-care. He was refused admission because of a combination of being old, housebound, and on home oxygen.

\section{Requesting different information}

Some variation may have resulted from participants requesting different information about a case. Five of those who admitted case 4 did not ask for blood gases which were influential in the decisions made by those who refused admission. However, they were aware of both the frequent admissions and the CHF, which suggests that they considered exercise tolerance more important. Similarly, all but one of the participants who did not admit the patient was aware of the exercise tolerance, which suggests that they considered other factors more important.

In case 2 the information that was influential for those who admitted the patient (blood gases, co-morbidities, and signs of pneumonia) was known by two non-admitters, whilst one was aware only of the blood gases and another was aware only of the co-morbidities. All the participants who admitted the patient were aware of the exercise tolerance (reason for the decision by non-admitters). In case 3 , four of the six who did not admit the patient were aware of either the co-morbidities or the lack of admissions (reasons for the decision by the admitters). All the admitters were aware that the patient was old, housebound, and on home oxygen (reasons for non-admitters' decision).
Interpreting the same information differently

Differences were observed in the meaning attached to certain information such as co-morbidities and signs of pneumonia. Co-morbidities were considered insignificant by some respondents and reasons for refusing admission by others. For example, the past medical history of case 3 (Appendix) was seen negatively by some (ICU2: "Outcome will be poor. He has already got 3 or 4 organs that are impaired") and considered unimportant by others (Resp6: "None of what you've told me is an adverse prognostic factor. Carcinoma in '94 with no secondaries is cured, Paget's and glaucoma are irrelevant, it's ages since he had his infarct").

As the reason for the current exacerbation, pneumonia was considered a good prognostic factor by most: "She has got a reversible condition, a chest infection, and I think she should be given a chance" (Resp4, case 2). Two participants considered pneumonia a bad prognostic factor: "Pneumonia on chest $x$-ray would make the prognosis worse. It would make it acutely worse" (Respl, case 2).

\section{DISCUSSION}

The study identified three sources of variation in the decision whether or not to admit to the ICU and to ventilate a patient with COPD in acute respiratory failure. Importance might be attached to different criteria, resulting in a patient being admitted by a doctor on the basis of, for example, exercise

\begin{tabular}{|c|c|c|c|c|c|c|}
\hline Participant & Case 1 & Case 2 & Case 3 & Case 4 & Case 5 & Case 6 \\
\hline \multicolumn{7}{|c|}{ Respiratory doctors (Resp) } \\
\hline Respl & Yes & Yes & Yes & Yes & Yes & Yes \\
\hline Resp2 & Yes & Yes & Yes & No & No & Yes \\
\hline Resp3 & Yes & No & No & Yes & No & Yes \\
\hline Resp4 & Yes & Yes & No & No & No & - \\
\hline Resp5 & Yes & Yes & Yes & Yes & No & - \\
\hline Resp6 & Yes & No & Yes & Yes & No & Yes \\
\hline Resp7 & Yes & No & No & No & No & Yes \\
\hline \multicolumn{7}{|c|}{ Intensive care doctors (ICU) } \\
\hline ICU 1 & Yes & Yes & Yes & No & No & Yes \\
\hline ICU 2 & Yes & Yes & Yes & No & No & Yes \\
\hline ICU 3 & Yes & Yes & Yes & Yes & Yes & Yes \\
\hline ICU 4 & No & Yes & No & No & No & - \\
\hline ICU 5 & Yes & No & No & Yes & No & Yes \\
\hline ICU 6 & Yes & Yes & No & Yes & No & Yes \\
\hline ICU 7 & Yes & Yes & Yes & Yes & No & Yes \\
\hline
\end{tabular}


tolerance and being refused admission by another doctor on the basis of, for example, co-existing heart disease, even though both doctors are aware of both criteria. Differences in the weighting of information have also been found in judgement analysis studies. ${ }^{23}$

The second source of variation indicates disagreement as to what information is relevant. Different information may be requested by different doctors and critical information may be omitted. In the absence of agreed guidelines about what information to collect, a plausible "story" presented to the decision maker and framed according to a colleague's expectations about clinical outcome ${ }^{24}$ may obscure omissions of critical information and appear more reliable and diagnostic than it is. ${ }^{25}$ A recent NICE guideline on the management of COPD exacerbations recommends seven items of information to be taken into account when assessing patient suitability for intubation and ventilation. ${ }^{26}$ This could in theory reduce the second source of variation. However, integrating several items of information (a "compensatory strategy" in decision psychology $y^{27}$ ) without some external aid is highly unlikely to be successful..$^{28}$

The final source of variation refers to differences in the interpretation of the same information. Some doctors may consider a specific co-morbidity to be a significant complicating factor while, for others, it may not affect prognosis. The presence of pneumonia may operate as "a ticket to the ICU" or compromise prognosis.

The importance, relevance, and meaning of clinical information are likely to be informed by experience. Doctors who make ICU admission decisions receive feedback only about the patients who were admitted. This limited feedback may affect future decisions by informing decision rules held in long term memory ${ }^{25}$ and can lead to idiosyncratic beliefs about how patient characteristics relate to clinical outcomes. ${ }^{29}$ This is compounded by confirmation bias which focuses attention on those patients who were admitted and discharged successfully rather than on those who were admitted and died in the ICU, ${ }^{30}$ thereby confirming that the decision rule was correct. Moreover, with hindsight, people tend to remember information consistent with the final outcome while de-emphasising contradictory or ambiguous information. ${ }^{31}$ Knowing that a patient who was admitted to the ICU died or survived to discharge focuses attention on clinical features consistent with that outcome while other important features may be forgotten.

\section{Study limitations}

The study design precluded large numbers of cases and participants. Statistical results therefore need to be interpreted with caution. There were significant differences between doctors in the amount of information requested, with some doctors consistently requesting little information and others engaging in almost exhaustive research. This suggests a strong influence of individual strategies. However, we do not know to what extent these reflect real life behaviour or differing perceptions of task demands. Even though the patients were "highly likely to arrest if not intubated and ventilated", different doctors may have perceived urgency differently. Under real time pressures, people use simple heuristics that need less information and do not integrate information. ${ }^{27}$ The ability of vignette studies to capture real life decisions has come into question ${ }^{32}$ but evidence is conflicting. ${ }^{33}$ Another reason why some doctors engaged in search intensive strategies is that they may have felt "accountable" to the investigator and requested more information than they would otherwise have done. ${ }^{34}$ Finally, inferring reasoning processes from verbal data has its limitations. ${ }^{35}$ Information that was influential for the participants, but was

\section{Key messages}

- Consistency in medical decision making (equity) is an important component of quality of care.

- Decision variation between clinicians can arise during (1) gathering information, (2) assessing its relative importance, and (3) interpreting information.

- To improve equity, all three potential sources of decision variation need to be acknowledged and addressed.

neither commented upon nor led to immediate changes in estimates, might have been missed.

\section{Reducing variation in decisions}

To improve equity, all three potential sources of variation need to be acknowledged and addressed: the clinical information relevant to the decision needs to be identified, interpreted correctly, and assessed for relative importance. Prognostic models use patient characteristics identified in prospective cohort studies to be associated with outcome, and combine the independent probabilities of survival associated with these characteristics to produce an overall survival estimate. However, prognostic models are difficult to apply in clinical practice without decision support due to limitations in human memory and information processing capacity, ${ }^{36}$ and also time pressures. Decision aids should be well integrated into the workflow and easy to apply so that clinicians can quickly assess individual patients.

The study suggests that cognitive factors-possibly due to individual clinicians' knowledge, experience and reasoning habits-are responsible for some of the variation in the decision even when patient, institution, and environment factors are kept constant. This type of variation is likely to be encountered in other uncertain medical decisions where no prognostic models exist or are difficult to use. Making the sources of variation explicit and known to clinicians might encourage them to acknowledge uncertainty and question their practice.

\section{Authors' affiliations \\ O Kostopoulou, Department of Primary Care and General Practice, University of Birmingham, Birmingham B15 2TT, UK \\ $M$ Wildman, Specialist Registrar in Respiratory Medicine, Critical Care Unit, City Hospital, Birmingham B18 7QH, UK \\ OK and MW conceived and designed the study. OK conducted the process tracing with the clinicians, analysed the results, and wrote the paper. MW obtained ethical approval, checked and standardised the cases, advised on medical issues, and commented on the paper. OK is the guarantor for the study. \\ OK is funded by a DoH R\&D/PPP National Primary Care Postdoctoral} Award.

\section{APPENDIX: CASES 1-6}

\section{CASE 1}

- Age and sex: 51 year old female.

- History of presenting complaint: worsening shortness of breath $(\mathrm{SoB})$ for 1 week following a cold such that patient cannot manage to climb stairs. Cough productive of yellow sputum.

- Exercise tolerance (in the period of stability): "restricted", can perform self-care

- COPD history: chronic bronchitis for at least 3 years. 
- Recent hospital admissions with SoB: one in the last 6 months.

- Past medical history: non-dialysis chronic renal failure, non-ulcer dyspepsia, hysterectomy, thyroidectomy.

- Current medications: thyroxine $150 \mu \mathrm{g}$, lansoprazole $30 \mathrm{mg}$, prednisolone $20 \mathrm{mg}$, erythromycin $500 \mathrm{mg}$ qds for 4 days

- Findings on examination: body mass index (BMI) 26, respiratory rate (RR) 50/min, pulse 120 , blood pressure (BP) 130/55, anxious, cold, able to say a few words. Chest: inspiratory and expiratory wheeze.

- Comments on chest $x$ ray: overexpanded, consistent with COPD, no focal consolidation.

- Comments on ECG: sinus tachycardia.

- Blood gases on admission: on air, $\mathrm{PaO}_{2} 7.1 \mathrm{kPa}, \mathrm{PaCO}_{2}$ $6.9 \mathrm{kPa}, \mathrm{pH} 7.29, \mathrm{HCO}_{3}{ }^{-} 25 \mathrm{mmol} / \mathrm{l}$.

- Full blood count: haemoglobin 9.8, white cell count 12.5, platelets 596.

- Urea and electrolytes: sodium $146 \mathrm{mmol} / \mathrm{l}$, potassium $3.6 \mathrm{mmol} / \mathrm{l}$, urea 12, creatinine 250, glucose 6 .

- Liver function tests: albumin 24, bilirubin 6, total protein 50, alkaline phosphatase 72 , alanine aminotransferase (ALT) 33.

- Self-rated QoL: poor.

- Social history: no information.

- Smoking: smoker, 50 cigarettes per day.

\section{CASE 2}

- Age and sex: 69 year old female.

- History of presenting complaint: cough and increasing wheeze for 1 day. Seen by GP who prescribed antibiotics.

- Exercise tolerance (in the period of stability): "housebound", can perform self-care.

- COPD history: known COPD.

- Recent hospital admissions with SoB: one with bronchopneumonia 4 months ago.

- Past medical history: non-insulin dependent diabetes mellitus (NIDDM) with no end-organ damage, high blood pressure, left-sided cerebrovascular accident (CVA) 1993 (minor sequelae).

- Current medications: Zopiclone $3.75 \mathrm{mg}$ nocte, lisinopril $10 \mathrm{mg}$, amlodipine $5 \mathrm{mg}$, bronchodilators (inhalers).

- Findings on examination: thin (BMI 18), looks unwell, temperature $38.5^{\circ} \mathrm{C}$, RR $40 / \mathrm{min}$, pulse 150 , BP $205 / 160$, heart sounds audible, no added sounds, jugular venous pressure (JVP) not raised, $\mathrm{O}_{2}$ saturations $98 \%$ on $35 \% \mathrm{O}_{2}$. Chest: widespread wheezes. Reduced air entry to both bases.

- Comments on chest $x$ ray: overexpanded, patch of consolidation.

- Comments on ECG: nil acute.

- Blood gases on admission: on $35 \% \mathrm{O}_{2}, \mathrm{PaO}_{2} 23.26 \mathrm{kPa}$, $\mathrm{PaCO}_{2} 10.42 \mathrm{kPa}, \mathrm{pH} 7.219, \mathrm{HCO}_{3}{ }^{-} 26.4 \mathrm{mmol} / \mathrm{l}$, base excess 2.2.

- Full blood count: haemoglobin 15.2, white cell count 15.9, platelets 304.

- Urea and electrolytes: sodium $147 \mathrm{mmol} / \mathrm{l}$, potassium $4.3 \mathrm{mmol} / \mathrm{l}$, urea 5.4, creatinine 54, glucose 10.2 . Urine free of ketones.

- Liver function tests: albumin 39, bilirubin 11, total protein 81, alkaline phosphatase 184, ALT 35.

- Self-rated QoL: good.

- Social history: lives in residential home.

- Smoking: smoker, 40 cigarettes per day.

\section{CASE 3}

- Age and sex: 83 year old male.

- History of presenting complaint: increasing SoB over the last 7 days. Seen by GP initially who prescribed antibiotics. His son was concerned that SoB has increased and brought him to hospital.

- Exercise tolerance (in the period of stability): "housebound", can perform self-care.

- COPD history: known COPD. On $\mathrm{O}_{2}$ from $\mathrm{O}_{2}$ concentrator.

- Recent hospital admissions with SoB: none in the last 6 months.

- Past medical history: myocardial infarction in 1995, stable angina, atrial fibrillation, glaucoma, Paget's disease, previous sigmoid colon carcinoma (Dukes' B) in 1994 with no secondaries.

- Current medications: Atrovent 2 puffs qds, terbutaline as required, beclamethasone 2 puffs bd, amoxycillin (recently started), GTN as required, digoxin $125 \mu \mathrm{g}$ od, aspirin $75 \mathrm{mg}$ od, nizatidine $150 \mathrm{mg}$ bd, timolol eye drops.

- Findings on examination: BMI 26, temperature $36.5^{\circ} \mathrm{C}$ axilla, RR 24/min, pulse 130 irregular, BP 150/80, JVP not raised, no evidence of DVT or ankle oedema. Chest: no wheeze, reduced air entry.

- Comments on chest $x$ ray: shadowing right lower zone. Presumed infection.

- Comments on ECG: atrial fibrillation-nil acute.

- Blood gases on admission: on air, $\mathrm{PaO}_{2} 7.2 \mathrm{kPa}, \mathrm{PaCO}_{2}$ $8.3 \mathrm{kPa}, \mathrm{pH} 7.21, \mathrm{HCO}_{3}{ }^{-} 28.1 \mathrm{mmol} / \mathrm{l}$.

- Full blood count: haemoglobin 14.9, white cell count 12.9, platelets 219.

- Urea and electrolytes: sodium $142 \mathrm{mmol} / \mathrm{l}$, potassium $4.7 \mathrm{mmol} / \mathrm{l}$, urea 8.7, creatinine 79, glucose 68 .

- Liver function tests: albumin 35, bilirubin 13, total protein 69, alkaline phosphatase 111, ALT 31, calcium 2.3.

- Self-rated QoL: very good.

- Social history: retired sheet metal worker. Lives with son and wife.

- Smoking: ex-smoker; stopped 50 years ago.

\section{CASE 4}

- Age and sex: 72 year old male

- History of presenting complaint: increasing SoB for 4 weeks. Rapid deterioration over the last 12 hours. Gradual reduction in exercise tolerance. Housebound for the last week.

- Exercise tolerance (in the period of stability): "restricted", can perform self-care.

- COPD history: known COPD.

- Recent hospital admissions with SoB: three in the last 6 months.

- Past medical history: known congestive heart failure (CHF).

- Current medications: salbutamol, Atrovent, beclamethasone $250 \mu \mathrm{g}$ bd, frusemide $80 \mathrm{mg}$ od, lisinopril $10 \mathrm{mg}$ od, prednisolone $40 \mathrm{mg}$ od (recently started).

- Findings on examination: obese (BMI 30), short of breath, unable to talk in sentences, RR $35 / \mathrm{min}$, pulse 94 regular, $\mathrm{BP} 92 / 58$, JVP raised, temp $37.5^{\circ} \mathrm{C}$, pitting oedema to midshin. Chest: bilateral coarse crackles right $>$ left. Expiratory wheeze on right.

- Comments on chest $x$ ray: over-expansion, consistent with COPD; big heart; pulmonary congestion.

- Comments on ECG: sinus tachycardia-nil acute. 
- Blood gases on admission: on $35 \% \mathrm{O}_{2}, \mathrm{PaO}_{2} 6.2 \mathrm{kPa}$, $\mathrm{PaCO}_{2} 8.6 \mathrm{kPa}, \mathrm{pH} 7.32, \mathrm{HCO}_{3}{ }^{-} 30.4 \mathrm{mmol} / \mathrm{l}$.

- Full blood count: haemoglobin 11, white cell count 11.4, platelets 166.

- Urea and electrolytes: sodium $128 \mathrm{mmol} / \mathrm{l}$, potassium $4.4 \mathrm{mmol} / \mathrm{l}$, urea 13.1, creatinine 81, glucose 7.2.

- Liver function tests: albumin 22, bilirubin 22, alkaline phosphatase 75, ALT 75, calcium 2.26.

- Self-rated QoL: fair.

- Social history: worked in a coal mine and a foundry (duration unknown). Lives with wife.

- Smoking: ex-smoker, stopped 15 years ago.

\section{CASE 5}

- Age and sex: 70 year old male.

- History of presenting complaint: cough and increasing SoB for 2 weeks. Had a brief respiratory arrest in ambulance. Short period of bag and mask ventilation. Increasingly oedematous. Deteriorating level of consciousness.

- Exercise tolerance (in the period of stability): "housebound", needs help washing.

- COPD history: known COPD for 10 years.

- Recent hospital admissions with SoB: two in the last 6 months.

- Past medical history: hypertension, CVA 25 years agomade full recovery.

- Current medications: Ventolin 2 puffs qds, Atrovent 2 puffs tds, Becotide $100 \mu \mathrm{g}$ bd, nifedipine $20 \mathrm{mg}$ bd.

- Findings on examination: thin (BMI <20), extremely breathless, RR $41 / \mathrm{min}$, temp $38.6^{\circ} \mathrm{C}$, pulse 102 regular, BP 98/58, JVP not raised, ankle oedema ++. Chest: right base dull to percussion-bronchial breathing right base with widespread crepitations on right side.

- Comments on chest $x$ ray: right lower lobe pneumonia.

- Comments on ECG: sinus rhythm, left axis deviation, ST segment flattening lateral leads.

- Blood gases on admission: on air, $\mathrm{PaO}_{2} 6.8 \mathrm{kPa}, \mathrm{PaCO}_{2}$ $8.4 \mathrm{kPa}, \mathrm{pH} 7.23, \mathrm{HCO}_{3}{ }^{-} 26.5 \mathrm{mmol} / \mathrm{l}$

- Full blood count: haemoglobin 12.6, white cell count 18.4, platelets 237.

- Urea and electrolytes: sodium $129 \mathrm{mmol} / \mathrm{l}$, potassium $3.4 \mathrm{mmol} / \mathrm{l}$, urea 7, creatinine 89, glucose 7.2.

- Liver function tests: albumin 27, bilirubin 8 .

- Self-rated QoL: poor.

- Social history: worked in a brewery and as a lorry driver. Lives with son. Moderate alcohol intake.

- Smoking: ex-smoker.

\section{CASE 6}

- Age and sex: 85 year old male

- History of presenting complaint: gradually worsening SoB over 2-3 days. Cough productive of whitish sputum.

- Exercise tolerance (in the period of stability): "restricted", able to perform self-care.

- COPD history: known COPD. Problems for 3 years-only in winter months-no problems in summer.

- Recent hospital admissions with SoB: none in the last 6 months.

- Past medical history: hypertension, NIDDM.

- Current medications: Ventolin inhaler.
- Findings on examination: BMI 25, very breathless, unable to talk in sentences, RR $40 / \mathrm{min}$, temp $37.8^{\circ} \mathrm{C}$, pulse 108 regular, BP 160/92, JVP not raised, no ankle oedema. Chest: $\mathrm{O}_{2}$ saturations $80-85 \%$ on $2 \mathrm{l} / \mathrm{min}$, bilateral decreased air entry, few crepitations right base, hyperresonant to percussion, minimal wheeze.

- Comments on chest $x$ ray: hyperexpanded lung fields.

- Comments on ECG: sinus tachycardia, ST segment depression laterally.

- Blood gases on admission: on $2 \mathrm{l} / \mathrm{min} \mathrm{O}_{2}, \mathrm{PaO}_{2} 7.13 \mathrm{kPa}$, $\mathrm{PaCO}_{2} 8.22 \mathrm{kPa}, \mathrm{pH} 7.318, \mathrm{HCO}_{3}{ }^{-} 30.9 \mathrm{mmol} / \mathrm{l}$, base excess +3.0

- Full blood count: haemoglobin 14.4, white cell count 21.7, platelets 467.

- Urea and electrolytes: sodium $151 \mathrm{mmol} / \mathrm{l}$, potassium $3.9 \mathrm{mmol} / \mathrm{l}$, urea 25.5, creatinine 102, glucose 14.5 .

- Liver function tests: albumin 35, bilirubin 6.

- Self-rated QoL: good.

- Social history: retired moulder. Lives alone. Family visit regularly. Occasional alcohol.

- Smoking: lifelong smoker, 15 cigarettes/day at present.

\section{REFERENCES}

1 Casparie AF. The ambiguous relationship between practice variation and appropriateness of care: an agenda for further research. Health Policy 1996:35:247-65.

2 Hill KM, Muers MF. Palliative care for patients with non-malignant end stage respiratory disease. Thorax 2000;55:979.

3 Wildman M, Goldfrad C, Rowan K. Functional health following intensive care unit admission for patients with acute respiratory failure due to chronic obstructive pulmonary disease in the UK. Am J Respir Crit Care Med 1998;157:A18.

4 Marini JJ. Ventilatory management of COPD. In: Cherniack N, ed. Chronic obstructive pulmonary disease. Philadelphia: WB Saunders, 1991:495-507.

5 Department of Health. Guidelines on the admission and discharge from intensive care and high dependency. London: Department of Health, 1996.

6 Degner LF, Sloan JA. Decision making during serious illness: what role do patients really want to play? J Clin Epidemiol 1992;45:941-50.

7 Connors AF, Dawson NV, Thomas C, et al. Outcomes following acute exacerbation of severe chronic obstructive lung disease. Am J Respir Crit Care Med 1996; 154:959-67.

8 Poses RM, Bekes CB, Copare FJ, et al. The answer to "What are my chances, Doctor? " depends on who is asked: prognostic disagreement and inaccuracy for critically ill patients, Crit Care Med 1989;17:827-33.

9 Christakis NA, Lamont EB. Extent and determinants of error in doctors' prognoses in terminally ill patients: prospective cohort study. BMJ 2000;320:469-73.

10 Pearlman RA. Variability in physician estimates of survival for acute respiratory failure in chronic obstructive pulmonary disease. Chest 1987;91:515-21.

11 Pearlman RA, Inui TS, Carter WB. Variability in physician bioethical decisionmaking. Ann Intern Med 1982;97:420-5.

12 Einhorn HJ. Expert judgment: Some necessary conditions and an example. J Appl Psychol 1974;59:562-71.

13 Shanteau J, Weiss DJ, Thomas RP, et al. How can you tell if someone is an expert? Performance-based assessment of expertise. In, Shanteau J, Schneider S, eds. Emerging perspectives on judgment and decision research Cambridge, Cambridge University Press, 2003:620-39.

14 Menzies R, Gibbons W, Goldberg P. Determinants of weaning and survival among patients with COPD who require mechanical ventilation for acute respiratory failure. Chest 1989;95:398-405.

15 Katz S, Downs TD, Cash HR, et al. Progress in development of the Index of ADL. Gerontologist 1970;10:20-30.

16 Marshall E, Duncan KD. Presented versus withheld and static versus dynamic information in process control training. Het Vennenbos, The Netherlands: NATO Conference on Visual Presentation of Information, 1978.

17 Duncan KD, Shepherd A. A simulator and training technique for diagnosing plant failures from control panels. Ergonomics 1975;18:627-42.

18 Duncan KD, Praetorius N. Knowledge capture for fault-diagnosis training Adv Man-Machine Systems Res 1987;3:165-78.

19 Huber O, Wider R, Huber OW. Active information search and complete information presentation in naturalistic risky decision tasks. Acta Psychol 1997;95:15-29.

20 Williamson J, Ranyard R, Cuthbert L. A conversation-based process tracing method for use with naturalistic decisions: an evaluation study. Br J Psychol 2000;91:203-21.

21 Ericsson KA, Simon HA. Protocol analysis: verbal reports as data. Cambridge, MA: MIT Press, 1984.

22 Miles MB, Huberman AM. Qualitative data analysis. Thousand Oaks, CA: Sage, 1994. 
23 Kirwan JR, Chaput de Saintonge DM, et al. Clinical judgment in rheumatoid arthritis. III. British rheumatologists' judgments of 'change in response to therapy'. Ann Rheum Dis 1984;43:686-94.

24 Sullivan KE, Hebert PC, Logan J, et al. What do physicians tell patients with end-stage COPD about intubation and mechanical ventilation? Chest 1996;109:258-64.

25 Wickens CD, Hollands JG. Engineering psychology and human performance. New Jersey: Prentice Hall, 2000.

26 National Collaborating Centre for Chronic Conditions. Chronic Obstructive Pulmonary Disease: national guideline on management of chronic obstructive pulmonary disease in adults in primary and secondary care. NICE guideline No 12. Thorax 2004;59(Suppl I): 1-232.

27 Gigerenzer G, Todd PM, and the ABC Research Group. Simple heuristics that make us smart. New York: Oxford University Press, 1999.

28 Simon HA. Invariants of human behavior. Ann Rev Psychol 1990:41:1-19.

29 Gonzalez-Vallejo C, Sorum PC, Stewart TR, et al. Physicians' diagnostic judgments and treatment decisions for acute otitis media in children. Med Decis Making 1998;18:149-62.
30 Einhorn HJ, Hogarth RM. Confidence in judgment: persistence of the illusion of validity. Psychol Rev 1978;85:395-416.

31 Dellarosa D, Bourne LE. Decisions and memory: differential retrievability of consistent and contradictory evidence. J Verb Learn Verb Be 1984; $23: 669-82$

32 Wigton RS. Social judgment theory and medical judgment. Thinking and Reasoning 1996;2:175-90.

33 Kirwan JR, Chaput de Saintonge DM, Joyce CRB, et al. Clinical judgment in rheumatoid arthritis. I. Rheumatologists' opinions and the development of 'paper patients'. Ann Rheum Dis 1983:42:644-7.

34 McAllister D, Mitchell TR, Beach LR. The contingency model for selection of decision strategies: an empirical test of the effects of significance, accountability, and reversability. Organ Behav Hum Dec 1979:24:228-44.

35 Bainbridge L. Verbal reports as evidence of the process operator's knowledge. Int J Human-Computer Studies 1999;51:213-38.

36 Redelmeier DA, Lustig AJ. Prognostic indices in clinical practice. JAMA $2001 ; 285: 3024$.

\section{Clinical Evidence-Call for contributors}

Clinical Evidence is a regularly updated evidence based journal available worldwide both as a paper version and on the internet. Clinical Evidence needs to recruit a number of new contributors. Contributors are health care professionals or epidemiologists with experience in evidence based medicine and the ability to write in a concise and structured way.

\section{Currently, we are interested in finding contributors with an interest in} the following clinical areas:

Altitude sickness; Autism; Basal cell carcinoma; Breast feeding; Carbon monoxide poisoning; Cervical cancer; Cystic fibrosis; Ectopic pregnancy; Grief/bereavement; Halitosis; Hodgkins disease; Infectious mononucleosis (glandular fever); Kidney stones; Malignant melanoma (metastatic); Mesothelioma; Myeloma; Ovarian cyst; Pancreatitis (acute); Pancreatitis (chronic); Polymyalgia rheumatica; Post-partum haemorrhage; Pulmonary embolism; Recurrent miscarriage; Repetitive strain injury; Scoliosis; Seasonal affective disorder; Squint; Systemic lupus erythematosus; Testicular cancer; Varicocele; Viral meningitis; Vitiligo However, we are always looking for others, so do not let this list discourage you.

\section{Being a contributor involves:}

- Appraising the results of literature searches (performed by our Information Specialists) to identify high quality evidence for inclusion in the journal.

- Writing to a highly structured template (about 2000-3000 words), using evidence from selected studies, within 6-8 weeks of receiving the literature search results.

- Working with Clinical Evidence Editors to ensure that the text meets rigorous epidemiological and style standards.

- Updating the text every eight months to incorporate new evidence.

- Expanding the topic to include new questions once every 12-18 months.

If you would like to become a contributor for Clinical Evidence or require more information about what this involves please send your contact details and a copy of your CV, clearly stating the clinical area you are interested in, to Claire Folkes (cfolkes@bmigroup.com).

\section{Call for peer reviewers}

Clinical Evidence also needs to recruit a number of new peer reviewers specifically with an interest in the clinical areas stated above, and also others related to general practice. Peer reviewers are health care professionals or epidemiologists with experience in evidence based medicine. As a peer reviewer you would be asked for your views on the clinical relevance, validity, and accessibility of specific topics within the journal, and their usefulness to the intended audience (international generalists and health care professionals, possibly with limited statistical knowledge). Topics are usually 2000-3000 words in length and we would ask you to review between 2-5 topics per year. The peer review process takes place throughout the year, and our turnaround time for each review is ideally 10-14 days.

If you are interested in becoming a peer reviewer for Clinical Evidence, please complete the peer review questionnaire at www.clinicalevidence.com or contact Claire Folkes(cfolkes@bmigroup.com). 